\title{
Cultura visual escolar: Investigación de los muros de primero básico*
}

\author{
School Visual Culture: Research about Primary School's Walls \\ Cultura visual escolar: Pesquisa das paredes do primeiro ano do ensino fundamental
}

\author{
Luis Hernán Errázuriz, ${ }^{a}$ Carlos Portales. ${ }^{b}$ \\ ${ }^{a}$ Instituto de Estética, Facultad de Filosofía, Pontificia Universidad Católica. Avda. Jaime Guzmán Errázuriz \\ 3.300, Providencia, Santiago, Chile. Fono: 56-2-2-6865240. Correo electrónico: lerrazur@puc.cl

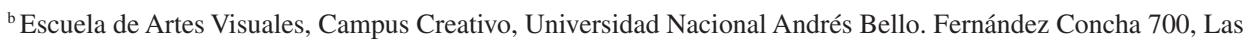 \\ Condes, Santiago, Chile. Fono: 56-2-2-4581996. Correo electrónico: carlosportalesg@gmail.com
}

\begin{abstract}
RESUMEN
Uno de los temas más descuidados de la educación es la dimensión estética del entorno escolar y su posible impacto en la calidad de la enseñanza. Este artículo aborda la cultura visual desplegada en los muros de las salas de clases, correspondientes a los primeros básicos de 13 establecimientos municipales de la comuna de Peñalolén. En términos más específicos, da cuenta de los propósitos de las imágenes, su procedencia, tecnología, iconografía y estilo, cuyos resultados muestran una cuantiosa y variada proliferación de visualidades, a partir de las cuales surgen interrogantes en cuanto a los criterios de su selección y pertinencia en el contexto educativo, así como también sobre la participación de los estudiantes en su producción.
\end{abstract}

Palabras clave: educación, estética cotidiana, cultura visual escolar.

\begin{abstract}
One of the most overlooked topics of education is the aesthetic dimension of school's environment and its possible impact upon teaching quality. This paper ponders over the visual culture unfolded in classrooms' walls of the first year of primary school in public educational establishments of the area of Peñalolén. Specifically, this research studies the purposes of the images, its sources, technologies, iconographies, and styles. The results show a copious and varied proliferation of images, which raise certain questions related to the criteria of their selection and their suitability in the educational context, as well as the students' participation in their production.
\end{abstract}

Key words: education, everyday aesthetics, school visual culture.

\section{RESUMO}

Um dos temas mais ignorados da educação é o da dimensão estética do entorno escolar e seu possível impacto na qualidade do ensino. Aborda-se a cultura visual refletida nas paredes das salas de aula de primeiros anos do Ensino Fundamental de treze escolas municipais do bairro de Peñalolén, em Santiago do Chile. Mais especificamente, enfoca no propósito das imagens, suas procedências, tecnologia, iconografia e estilo, cujos resultados mostram uma grande e variada proliferação de visualidades, a partir das quais surgem interrogativas em relação aos critérios de seleção e pertinência das imagens no contexto educativo, bem como questionamento sobre a participação dos estudantes na elaboração das mesmas.

Palavras chave: educação, estética cotidiana, cultura visual escolar.

\footnotetext{
* El presente artículo forma parte de la investigación Fondecyt (Fondo Nacional de Investigación Científica y Tecnológica),
} Proyecto Nº 1120058, (2012-2013): "La estética cotidiana en establecimientos escolares de la comuna de Peñalolén". 


\section{INTRODUCCIÓN}

Pegar y exhibir imágenes en las paredes tales como láminas didácticas, mapas, figuras históricas, héroes, símbolos patrios, personajes infantiles de la televisión y/o la publicidad, reproducciones de paisajes, decoraciones, entre otras, constituye un rasgo distintivo de la cultura escolar -especialmente en los primeros cursos de la enseñanza primaria-, cuya persistencia en el tiempo pareciera resistir incólume en un mundo cada vez más digitalizado. Esta práctica es de larga data en la historia de la educación chilena, la que ha recibido fuerte influjo extranjero ${ }^{1}$. En efecto, hace más de un siglo que las imágenes son utilizadas en los muros de las escuelas no sólo como recurso pedagógico, sino también con propósitos ideológicos, sociales y religiosos.

Paradojalmente, aunque vivimos en un mundo saturado de imágenes, los temas de la visualidad y la estética del entorno escolar no figuran en la candente agenda educacional. La ausencia de investigación y de orientaciones en torno a éstos así lo evidencia: poco o nada se ha indagado en nuestro país acerca de la dimensión estética de la enseñanza escolar, por ejemplo, la cultura visual de sus muros, la realidad material, espacial y lumínica de los ambientes pedagógicos. Desde esta perspectiva cabe formular algunas preguntas que, aunque desbordan el propósito de este artículo, deben ser consideradas: ¿En qué sentido la estética del entorno escolar podría contribuir a mejorar la calidad de la educación? ¿Qué propósitos -o despropósitos- se le confiere a la visualidad en los muros escolares?

A la luz de estas interrogantes, el siguiente trabajo concentra la atención en las imágenes que "ambientan" la sala de clases con el objeto de visibilizar aspectos que suelen pasar inadvertidos o simplemente son ignorados y que, sin embargo, en virtud de su relevancia pedagógica y estética, requieren ser investigados con una mirada reflexiva y crítica.

Con esta finalidad, primeramente se abordan de un modo sucinto tres conceptos fundamentales: estética cotidiana, cultura visual y currículo oculto, en torno a los cuales se sustentan las bases teóricas del estudio. Luego de explicitar la metodología empleada en la investigación, se presentan los resultados del trabajo en terreno, en relación con los propósitos de las imágenes investigadas, su procedencia, tecnología, iconografía y estilo. Finalmente, se esbozan algunas conclusiones a partir de las cuales se pueden plantear nuevas interrogantes y líneas de investigación.

\subsection{ESTÉTICA COTIDIANA, CULTURA VISUAL, CURRÍCULO OCULTO}

La proliferación de estudios en torno a la estética cotidiana, a propósito de su influencia en diversos campos disciplinares, es cada vez mayor. La primera en advertir de un modo más explícito la importancia de este campo de estudio fue Katya Mandoki², quien reivindica el valor que lo cotidiano posee en términos estéticos y cómo ello afecta numerosos territorios de nuestra vida diaria. La autora proyecta sus argumentos a partir de la noción de "prosaica", que es "la sensibilidad en la vida cotidiana" (2007: 76-77; 1994: 83) distinto a la "poética", que se vincula a "la sensibilidad en la producción artística" (2007: 75; 1994: 83).

Véase, por ejemplo: Orellana, M. I. y Martínez, M. F. (2010). Educación e Imagen: Formas de modelar la realidad. Serie: Itinerario y Memoria del Bicentenario. Archivo Visual del Museo de la Educación Gabriela Mistral.

Investigadora de la Universidad Autónoma de México, quien acuñó el concepto estética cotidiana en su libro Prosaica: Introducción a la estética de lo cotidiano de 1994. 
Una perspectiva similar es la que asumen Arto Haapala (2005) y Yuriko Saito (2007), al denunciar la marginalidad sistemática de lo cotidiano en el campo de los estudios estéticos tradicionales. Haapala insiste en la importancia de la relación entre el lugar y la sensibilidad estética, en el contexto de nuestra vida diaria.

Por su parte, Saito propone una "estética de lo cotidiano" que haga justicia a la heterogeneidad de la vida que experimentamos día a día, incluyendo cualquier reacción que podamos tener ante las cualidades sensibles de un objeto, fenómeno o actividad (2007: 9); con ello abarca tanto las respuestas placenteras como las de desagrado, lo cual constituye un aporte muy significativo en un contexto en que la estética suele restringirse al discurso sobre la belleza y las artes.

A partir de la importancia que otorgan estos autores a la experiencia estética de los lugares cotidianos, resulta ineludible considerar la sala de clases como uno de esos espacios rutinarios que deben ser explorados estéticamente, tomando en cuenta no sólo sus características placenteras, sino también aquellas que resultan desagradables o inapropiadas en el contexto escolar. Siguiendo la argumentación de Haapala, la configuración estética de la sala de clases resultaría significativa no solamente para la rutina de los individuos por separado, sino también para las relaciones que éstos establecen como grupo y con el ambiente de enseñanza y aprendizaje.

Coincidiendo con esta intención, Mandoki esboza un tipo de matriz estética escolar determinada por su función. Al respecto, plantea que la puerta de la escuela funciona como espacio liminal de transición, un umbral que al cruzarlo se ingresa a "otro mundo" (1994: 208). Este otro mundo en términos de sensibilidad es sostenido por la matriz escolar, cuyas principales características visuales serían la tendencia hacia la homogeneidad, y en ciertos aspectos, un parecido relativo a las visualidades empresariales, burocráticas e industriales. Dichos rasgos, según la autora, son correlativos a la función de la institución escolar, correspondiente a la separación del individuo del aparato familiar -con el cual la institución escolar estaría en una competencia política en su rol de formación de sujetos-, y a la preparación para ingresar a la matriz laboral y estatal (1994: 199).

Otro concepto fundamental para el presente estudio es el de cultura visual, que fue acuñado por primera vez por Svetlana Alpers en su libro The Art of Describing: Dutch Art in the Seventeenth Century (1983), para referirse a las capacidades visuales de los pintores flamencos del siglo XVII, que les habrían permitido mayor agudeza en la observación de la realidad.

La noción de cultura visual coincide con la de estética cotidiana en cuanto es postulada como un quiebre en el modo de concebir los estudios visuales. Ésta cuestiona la distinción canónica entre medios, democratizando el valor de cada imagen, independientemente de su proveniencia; sea clasificada como artística o no (Dikovitskaya, 2006: 53). En otras palabras, considera experiencias visuales que ocurren fuera de "momentos estructurados del mirar" -cine, televisión, galerías de arte, fotografía, etc.- (Mirzoeff, 1999: 7), incluyendo así aquellas imágenes que encontramos en la vida cotidiana y que, en el caso del presente estudio, corresponden a las visualidades desplegadas en los muros de las salas de clases.

La mayoría de los autores parece coincidir en que el término de "cultura visual" niega la idea de sostener todo tipo de inmediatismos en materia visual. En este sentido, se sospecha que "[e]ntre el sujeto y el mundo se inserta la entera suma de discursos que construyen la visualidad [...] y que hacen que la visualidad sea algo distinto a la visión, la noción de experiencia visual sin mediación" (Bryson, 1988: 94). Extrapolando lo dicho 
a las visualidades de las salas de clases, es posible afirmar que entre las imágenes y los estudiantes existen mediaciones culturales. Estas mediaciones no son en absoluto neutras ni mucho menos inocentes; siempre se encuentran en articulación con discursos sociales, mapas de significado e ideologías determinadas, vale decir, transmiten un tipo de mensaje y constituyen parte importante de la interacción o socialización cultural del estudiante.

En estrecha relación con la cultura visual y el mundo de la educación encontramos el término curriculum visual oculto. La noción de currículum oculto fue acuñada por el pedagogo norteamericano Philip W. Jackson en su obra Life in Classrooms (1968), para referirse al conjunto de contenidos que se transmiten de forma implícita en un contexto educativo. Generalmente es tratado como un elemento negativo en la educación, en cuanto promueve sesgos propios de corrientes ideológicas dominantes, que se filtran en el proceso pedagógico e interfieren con el desarrollo intelectual de los estudiantes (Cornbleth, 1984). En este sentido se considera que el currículum oculto induce a los estudiantes hacia ciertas creencias y comportamientos que refuerzan el orden hegemónico (Apple \& King, 1983).

Por su parte, Eric Margolis (1999) propone la paradoja de un "currículum visible pero oculto": busca la noción de un currículum compuesto de visualidades que es, sin embargo, implícito al ser parte accesoria del dispositivo escolar; no es un contenido explícito de lo que se enseña. Ser visible y oculto al mismo tiempo levanta nuevas problemáticas, ya que no está formado por mensajes escondidos en dinámicas recreacionales o en vivencias del espacio de los establecimientos escolares, sino que se expone impunemente a la vista. Sin embargo, se pierde al ser subsumido en la cultura escolar cotidiana, donde puede pasar como decoración o adorno. Desde este lugar refleja una cultura "incuestionable e inconsciente" (Schein, 1992: 239) de visualidades implícitas en la cotidianidad y "dadas por hecho" en la experiencia escolar.

Recapitulando lo dicho, la reseña de cada uno de los conceptos mencionados puede contribuir de un modo significativo al estudio de las imágenes de la sala de clases. La estética cotidiana recuerda la importancia que tienen las propiedades sensibles de los espacios propios de la rutina diaria en las relaciones afectivas y éticas de los individuos. Por otra parte, la cultura visual insiste en la necesidad de un análisis crítico sobre las visualidades que se presentan "fuera de momentos estructurados del mirar", argumentando acerca del en absoluto inocente poder de las imágenes a las que estamos expuestos en la vida diaria. Consiguientemente, la idea de currículo visual oculto viene a coronar esta línea argumentativa, al afirmar la insospechada pero crucial injerencia de las visualidades de las salas de clases en -y más allá- de los procesos pedagógicos escolares.

\section{METODOLOGÍA}

La presente investigación empleó una aproximación cualitativa utilizando categorías de análisis emergentes ${ }^{3}$, por medio de una observación no participante ${ }^{4}$. A modo de complemento, se realizó una clasificación cuantitativa, que tiene como objetivo servir de apoyo para el trabajo de carácter cualitativo.

Las temáticas y conceptos para clasificar los datos surge de la observación del material de estudio, vale decir, no se determinan a priori.

$4 \quad$ Coincidiendo así con algunas de las principales metodologías utilizadas en la interpretación de materiales visuales en el área de Estudios Visuales. Véase: Rose, G. (2001). Visual Methodologies. London: Sage. 
La selección muestral corresponde a las imágenes que se registraron en salas de clases de 13 establecimientos municipales de la comuna de Peñalolén, correspondientes a la Región Metropolitana en la ciudad de Santiago. El trabajo de campo se desarrolló hasta que se cubrió la diversidad del espectro de información, es decir, hasta que se alcanzó el punto de saturación ${ }^{5}$.

A partir de la recolección de datos, emergieron tres categorías de análisis primarias.

- Propósito de las imágenes: alude a la función o funciones que presumiblemente cumple cada imagen. Esta categoría se define bajo el supuesto de que no todas cumplen un fin didáctico y/o pedagógico, por lo que resulta significativo indagar qué otros propósitos se advierten en las visualidades de la sala de clases.

- Procedencia de las imágenes: dice relación con la(s) institución(es) o persona(s) que produce(n) las imágenes y, por lo tanto, aporta antecedentes para dilucidar quién o quiénes, directa o indirectamente, influyen y/o "editan" los contenidos visuales que se exhiben en los muros.

- Tecnología de las imágenes: busca identificar los diferentes métodos de producción usados para fabricar las imágenes y sus posibles nociones y/o implicancias culturales, educativas y pedagógicas.

Finalmente, como consecuencia del análisis de las categorías mencionadas surge una dimensión transversal que aborda el estilo y el contenido visual de las imágenes.

\section{PRESENTACIÓN DEL ESTUDIO}

Una de las primeras impresiones que se obtiene al visitar las salas de clases de los primeros básicos es la basta cantidad de imágenes que se despliegan en sus muros. De esta sobresaturación de estímulos visuales, se puede inferir la importancia que se le confiere a la imagen en la cultura escolar del primer ciclo básico. Esto coincide con algunas de las salas estudiadas por Augustowsky (2003) en Argentina, y con lo reportado como regla general por Read (2010) en Estados Unidos, sólo por nombrar algunos casos.

No obstante, una observación más detenida de los muros observados deja entrever cierto descuido en cuanto a los criterios de selección y la ubicación de las imágenes en el muro. En efecto, no parece haber una planificación cuidadosa respecto a la selección de las visualidades. Es por esta razón que para el presente trabajo se generaron algunas categorías con el objeto de dilucidar y clasificar sus características más representativas, a partir de un primer acercamiento al estudio de la cultura visual escolar.

\subsection{PROPÓSITOS DE LAS IMÁGENES}

Los propósitos predominantes que se desprenden de la observación de las imágenes fueron categorizados en cuatro tipos: formativo, didáctico, publicitario y decorativo. El propósito formativo responde a cualquier mensaje que intente inculcar alguna noción valórica, hábitos referentes a un estilo de vida, costumbres, conocimientos cívicos o creencias

Vale decir, cuando el material estudiado ya no otorgaba nuevos datos. 
ideológicas. Estas imágenes constituyen el 19\% de las unidades cuantificadas, vale decir, de 332 imágenes $^{6}, 63$ cumplen un propósito formativo ${ }^{7}$. Analíticamente es posible definir al menos cinco ámbitos formativos: imágenes que promueven valores "universales" (por ejemplo: amistad, amor, solidaridad, etc.), hábitos de normalización, campañas de utilidad pública, nociones patrióticas y, finalmente, una minoría que promueve nociones cristianas.

Sobre las imágenes de contenido patriótico, llama la atención la abundancia y selección de recursos gráficos utilizados para inculcar nociones de patria. En cuanto a la presencia de próceres, abundan las imágenes de Arturo Prat y Bernardo O’Higgins, ya sea en su tradicional retrato, o bien como caricaturas. En cuanto a los poetas nacionales, destaca la imagen de Gabriela Mistral. Por otro lado, encontramos los infaltables símbolos patrios que incluyen, principalmente, la bandera, el escudo y el copihue en variados diseños. Finalmente, se despliegan también imágenes relativas a la "chilenidad", como decorados de fonda o bien imágenes de huasos y otros motivos asociados a la identidad nacional, inclusive de orden culinario. Sin embargo, la presencia de estos íconos es correlativa a la ausencia de otros vinculados también a la noción de patria. Se extrañan referencias, por ejemplo, a las culturas pre-colombinas y el mundo indígena en general, así también a poetas y artistas nacionales -con la excepción de Gabriela Mistral- o bien al patrimonio cultural chileno. En este sentido, pareciese privilegiarse un planteamiento de identidad nacional monolítico, relativo al reducido conjunto de elementos tradicionales que implicaría la chilenidad.

Por otro lado, también encontramos imágenes que promueven hábitos regulatorios y disciplinarios relativos a la normalización de los estudiantes, como, por ejemplo, cuadros horarios y calendarios que establecen temporalidades para organizar actividades, o bien reglamentos deportivos y de seguridad, pero principalmente, conductas que se promueven dentro y fuera de la sala. Las conductas en la sala muestran hábitos de disciplina tales como sentarse derecho o pedir la palabra alzando la mano; mientras aquellas fuera de la sala se relacionan principalmente con hábitos de aseo e higiene. Resulta interesante el hecho de que en muchas de estas imágenes se utilicen figuras de niños(as) para ilustrar las instrucciones o bien como portavoces de aquellos mensajes, buscando que los escolares se identifiquen así con los referentes visuales.

Las imágenes con propósitos didácticos son aquellas que se encuentran relacionadas con procesos formales de enseñanza, y constituyen la mayoría de las aquí cuantificadas, alcanzando un 63,3\%, equivalente a 210 imágenes de un total de 332. Este tipo de imágenes corresponde principalmente a los elementos gráficos empleados por el método de lectoescritura, que usa letras y figuras. También, en menor proporción, números, conceptos y contenidos misceláneos de las ciencias sociales y naturales.

En general, se busca hacer una asociación entre elementos del material curricular -tales como letras y números- y expresiones gráficas como figuras y/o colores. Esta estrategia emula -especialmente en el caso de la lectoescritura- la tradicional herramienta pedagógica conocida como silabario. Al analizar el material visual, llaman la atención dos características estéticas accesorias: la primera dice relación con la disparidad y variedad estilística entre

\footnotetext{
La unidad de análisis empleada para la contabilización de las imágenes está constituida por "soportes gráficos únicos". No se cuantificaron aquellas imágenes cuya presencia se encuentra más de una vez, esto es, afiches, cuadros, posters o recortes que se repiten. En este sentido, cada "soporte gráfico único" es equivalente a una unidad contabilizada como caso. Bajo esta unidad de análisis se alcanza un total de 332 casos.

Cabe señalar que pese a que existen 63 imágenes formativas, muchas de éstas se repiten varias veces, otorgándole a esta categoría una presencia no reducible al mero conteo de imágenes únicas. Lo mismo puede ocurrir en otros casos.
} 
grupos de láminas, como si su procedencia fuera de diferentes ediciones de silabarios, mientras otras son simplemente calcadas a mano de esos textos; la segunda refiere a que muchas imágenes parecen desactualizadas, en tanto estilo y selección iconográfica, si se comparan con imágenes contemporáneas provenientes de la industria cultural infantil o la publicidad. En otras palabras, estas láminas en los muros parecen un collage de imágenes recicladas de viejas ediciones de silabarios, lo que denota la precariedad del material visual.

Si bien las imágenes con propósitos didácticos y formativos parecen obedecer a la lógica de los objetivos escolares, llama la atención la presencia de imágenes publicitarias, así como también de aquellas que no parecen tener ningún fin en particular más que servir de decorado. En cuanto a las primeras, cabe señalar que resulta cuestionable -por no decir inaceptable- que haya imágenes publicitarias en el ámbito escolar-especialmente aquellas que persiguen fines de lucro-, ya que si se revisan bajo un criterio pedagógico, éstas tienen propósitos que no coinciden en absoluto con los objetivos fundamentales y los contenidos mínimos establecidos por ley para la enseñanza.

Por su parte, la presencia de imágenes decorativas, sin ninguna función u objetivo específico -que constituyen alrededor de un 20\%-, evidencia la importancia que se le otorga al despliegue de elementos visuales en las salas observadas independiente de su propósito, vale decir, estas imágenes parecieran tener valor en sí mismas en el espacio educativo escolar, lo que evidencia la necesidad de cubrir, saturar los muros antes que dejarlos libres de decorado. En este caso resulta difícil establecer algún propósito o criterio que justifique su presencia más que uno estético. Sin embargo, esto constituye un aspecto idealmente requerido en crear un ambiente adecuado para niños, donde no solamente debiesen haber elementos visuales funcionales, sino también componentes meramente estéticos convergiendo en una relación armónica (Read, 2010: 75).

\subsection{PROCEDENCIA DE LAS IMÁGENES}

Las imágenes observadas tienen una procedencia muy heterogénea. Con excepción de un número limitado de casos, éstas no exhiben ningún tipo de registro que dé cuenta de su origen. Identificar su fuente resulta aún más complejo por el hecho de que muchas imágenes parecen recicladas (extraídas, calcadas o copiadas) de antiguos textos didácticos como silabarios y libros para colorear. Sin embargo, se puede establecer una distinción básica entre imágenes producidas fuera del establecimiento educacional e imágenes producidas dentro de éste.

Las de procedencia externa son muy abundantes en los muros de las salas de clases, constituyendo un 44,9\%. Ciertas fuentes resultan explícitamente identificables, ya sea por mostrar un sello de la institución que las produjo o bien por su contenido. Pese a que este tipo de imágenes, de procedencia identificable, no constituye la mayoría, resulta significativo constatar la presencia de agentes externos a los establecimientos escolares que inciden por medio de imágenes en la estética cotidiana de los alumnos, tales como el gobierno, el municipio, la iglesia, marcas comerciales, la UNICEF y los medios de comunicación.

Por otro lado, encontramos copiosas imágenes reconociblemente externas, pero cuya procedencia específica no resulta posible establecer. Éstas provienen presuntamente de una variedad de fuentes, y pueden agruparse en dos tipos: por un lado, las que corresponden a la industria dedicada a la producción de material escolar, como por ejemplo los métodos de lectoescritura, silabarios, etc.; y, por otro, las procedentes de la industria de los productos infantiles, tales como revistas ilustradas para niños, libros para colorear, adornos de fiestas 
como Halloween y cumpleaños, etc. Éstas constituyen el 34,9\% del total de imágenes y provienen de lo que se ha denominado industria infantil/escolar. Tienen en común cierto estilo y selección iconográfica que a grandes rasgos se reconoce por el diseño tipo caricatura y el uso de la personificación, cuando se trata de animales y objetos. En este sentido, parecen apelar a un estilo y contenido que se presupone infantil, similar al de viejas películas animadas, tales como aquellas producidas por Disney y Hanna Barbera, entre otras.

En forma paralela, las imágenes de procedencia interna se contabilizan en un 55,1\% (incluyendo imágenes externas pero modificadas internamente). Éstas se caracterizan por estar confeccionadas con tecnologías más precarias, generalmente manuales, o bien, en menor grado, con fotografías y no requieren mayores medios de producción. Técnicamente evidencian poca destreza, así como también menor calidad en su diseño. Muchas veces son calcadas, copiadas o recortadas (intervenidas) de imágenes externas, lo que denota que la selección iconográfica no se caracteriza por ser muy original.

Sin embargo, en algunos casos parecen lograr mayor originalidad y/o cercanía con los alumnos que las imágenes externas. Esto principalmente por dos medios: el uso de fotografías de los mismos alumnos o de espacios del colegio, donde la imagen reproduce visualidades de la cotidianidad de los estudiantes; $y$, en segundo lugar, cuando las imágenes no son ni fotografías, ni copias de producciones gráficas internas, su estilo es muchas veces similar al del dibujo infantil. Si bien esto no implica necesariamente originalidad en la selección iconográfica, sí exhibe un estilo diferente al mencionado estilo de caricatura imperante.

También hay imágenes directamente confeccionadas por los alumnos, que suelen representar una serie con la misma figura, lo cual indica que se trata de trabajos encargados por las profesoras. No obstante, hay que señalar que estas imágenes constituyen una cantidad muy reducida de la visualidad desplegada en los muros. Este hecho levanta el cuestionamiento acerca de la poca participación que parecen tener los estudiantes en la cultura visual producida en el muro de las salas de clases, hecho que pese a ser bastante común según muestran otros estudios, resulta importante revertir (Clark, McQuai \& Moss, 2003).

\subsection{TECNOLOGÍA DE LAS IMÁGENES}

A grandes rasgos, es posible categorizar la tecnología de las imágenes en tres tipos: aquellas cuya producción es realizada por medio de una impresión; las que son producidas manualmente, sin intervención de tecnologías electrónicas o mecánicas; y, finalmente, imágenes mixtas donde convergen ambas tecnologías.

Las imágenes impresas son externas, y generalmente son producidas por imprentas de uso industrial o profesional, vale decir, por medio de tecnologías de impresión que se utilizan para revistas, posters, diarios, etc. Este tipo de tecnologías es usado en un $65,7 \%$ del total de imágenes únicas. Se puede afirmar que las imágenes producidas con esta tecnología tienden a ser más sofisticadas y evidencian el uso de mayores recursos y pulcritud en el resultado, aunque no lo garantiza.

Las imágenes producidas manualmente y aquellas de técnica mixta suman un $34 \%$ de imágenes. Éstas recurren a materiales y medios de producción bastante variados, que son característicos de los cursos de primaria y que están relacionados a los útiles escolares, como los lápices grafito, de colores, escriptos, crayones, cartulinas, papel maché, témperas, tijeras, cola fría, etc. Con estos materiales se confeccionan imágenes con técnicas tales como el recorte, los coloreados, el pegoteo, el calco y otras. Las imágenes mixtas emplean 
casi los mismos recursos y técnicas de las manuales, variando solamente en el caso de las figuras, que generalmente son impresas.

Tanto las imágenes manuales como las mixtas pueden ser entendidas como una preservación de la producción artesanal, tipo de producción que predomina en las salas observadas. Es posible suponer que resultan más cercanas y familiares a los estudiantes que habitan la sala, ya que son producidas con tecnologías a su alcance, y porque además las técnicas utilizadas para producirlas son parte del "know how" de los docentes, y a veces se incluyen en el proceso de enseñanza de los alumnos.

\subsection{ICONOGRAFÍA Y ESTILO DE LAS IMÁGENES}

Las imágenes de la sala de clases se caracterizan por ser principalmente figuras, es decir, semblanzas de un objeto más que representaciones abstractas. Las figuras aluden mayoritariamente a animales y seres humanos, y aun cuando muestran objetos, los representan por medio de la personificación. Lo mismo sucede muchas veces en el caso de los animales que muestran rasgos humanos. Generalmente son representaciones de objetos fáciles de reconocer, como medios de transporte, objetos cotidianos, animales u otros, y que además tienden a repetirse en la mayoría de las salas observadas. En este sentido, la selección de figuras en las imágenes parece otorgar prioridad a aquellas que pretenden ser familiares, y que enfatizan la repetición para lograr una mayor efectividad en el proceso de reconocimiento.

Todo esto se relaciona con un imaginario específico que parece imponerse como criterio de gusto para los alumnos que cursan este nivel de enseñanza; imaginario que proviene en buena medida del mundo de la industria cultural infantil, como cómics, ilustraciones de libros de cuentos o producciones de dibujos animados del cine y la televisión. Ejemplos de ello son viejos personajes icónicos de este tipo de ficciones como "Winnie the Pooh" y la "Abeja Maya".

Pese a existir algunas imágenes televisivas contemporáneas, la mayoría pertenece a producciones mediáticas desconocidas, ya añejas o bien de presencia marginal en los medios, como personajes secundarios de famosas películas infantiles -por ejemplo, un candelabro de la "Bella y la Bestia" de Disney. Por otro lado, muchas figuras se asemejan a aquellas del mundo de la vieja industria cultural infantil, pero no es posible establecer si son o no extraídas de allí, ya que no resultan en absoluto conocidas, aunque sí estilísticamente familiares a este mundo. En este sentido, se puede hablar del predominio de un estilo que recuerda al mencionado imaginario de la industria cultural infantil de décadas pasadas, y que a grosso modo puede ser reconocido con la denominación de caricatura.

Este hecho contradice lo señalado por Mandoki acerca de la similitud entre la matriz estética escolar y aquellas de los mundos burocráticos o empresariales. La autora sostiene que éste es el caso porque la matriz escolar sirve como un espacio estético de transición entre la matriz del hogar y aquella del trabajo. Sin embargo, lo encontrado en el presente estudio parece indicar que la estética de las salas de clases despliega más bien una sensibilidad que busca la identificación con las visualidades que los alumnos encuentran en los medios de comunicación. Esta se caracteriza no por su gris homogeneidad, como afirma Mandoki, sino por el contrario, por visualidades bastante heterogéneas. Sin embargo, como se señaló, no pocas resultan bastante precarias y anacrónicas en comparación a lo que los medios de comunicación actuales exhiben, lo que no parece muy consistente si lo que se busca es identificación con un estilo mediático más contemporáneo. 


\section{CONCLUSIONES}

El presente estudio ha permitido constatar ciertos rasgos característicos de la cultura visual desplegada en las salas de clases de los primeros básicos en los establecimientos investigados. Cuatro aspectos llaman la atención en forma recurrente: la saturación visual de los muros, a causa de la gran cantidad de imágenes que se adhieren a ellos; el estilo anacrónico y precario de no pocas de estas imágenes; la escasa participación de los estudiantes en la creación de una iconografía que dé cuenta de sus ideas e intereses, modos de ver y comprender el mundo que los rodea; y finalmente, las inclusiones -y exclusiones- de tópicos y contenidos que evidencian la ineludible parcialidad de la construcción visual del muro.

Pareciera no haber orientaciones, criterios o planificación respecto a por qué, cómo y en qué medida es necesario o conveniente intervenir los muros con imágenes, casi como respuesta a un "impulso" por no dejar espacios vacíos, "neutros", libres de estímulos visuales. Nos encontramos así con paredes atiborradas de decoraciones, figuras, retratos, cuadros, símbolos, etc. No pocos de los cuales también evidencian cierto descuido en el diseño y organización del conjunto visual. En otras palabras, el diseño, producción y despliegue de esta cultura visual carece de una adecuada planificación desde una perspectiva estético-pedagógica, lo que contribuye al deterioro de la calidad del entorno educativo y, por ende, de la educación.

La mayoría de las imágenes que corresponden a la denominada industria escolar/ infantil se caracterizan por su anacronismo, por cuanto el imaginario que sustenta la iconicidad de muchas figuras del aula responde a uno generacionalmente desarraigado, vale decir, que se basa en una imaginería propia del período infantil de otras generaciones -ahora adultas- y no de los alumnos(as) que cursan primero básico. En este caso podría hablarse de la transmisión de gustos que hacen adultos basándose en su propia vivencia de cuando eran niños, lo que implica una imposición de imaginarios a los alumnos.

Por su parte, la variedad de fuentes y tecnologías empleadas en la producción de imágenes corresponde en buena medida a insumos iconográficos que provienen de instituciones externas -municipales, gubernamentales, organismos internacionales, empresas, otras-, las que suelen ser más sofisticadas que las elaboradas al interior de las escuelas. Este tipo de imágenes tiene una presencia prácticamente transversal en las salas de clases, lo cual podría indicar que corresponde a una de las pocas normativas que se imponen externamente (probablemente por parte del municipio).

Las imágenes elaboradas al interior de la escuela se caracterizan por ser técnicamente precarias. El contraste de este tipo de imágenes con aquellas de instituciones externas acentúa su falta de sofisticación. Pese a esto, se podría decir que estas imágenes presuponen que ha habido una elección del material visual por parte del establecimiento (docentes, asistentes, directores, etc.), lo que indicaría una mayor libertad.

Sin embargo, llama la atención que las imágenes internas generalmente no incluyen producciones realizadas por los mismos alumnos, y cuando lo hacen éstas responden a trabajos encargados por los docentes, en los que se limitan a colorear o dibujar todos una misma figura. En este sentido, es paradójico que si bien no parece haber normatividad para las imágenes elegidas por los profesores, sí hay una normatividad muy rígida para lo que los alumnos producen.

La intervención de un muro jamás es neutra, ya sea desde el punto de vista gráfico, cromático, o cualquier otro. No obstante, en el caso de los muros escolares, por tratarse de un 
espacio desregulado, vale decir, que puede ser intervenido -casi ilimitadamente- con diversos contenidos y estrategias visuales, su eventual pretensión de "neutralidad" es aún menor.

Esto se puede apreciar no solamente en lo que se muestra, sino también en aquello que se excluye. Por ejemplo, en el caso de las imágenes patrióticas, es posible cuestionar la casi inexistente representación de los pueblos indígenas; o bien, la ausencia de representaciones de cierto tipo de patrimonio cultural chileno, tales como el patrimonio natural o bien artístico, se excluyen personajes tan relevantes como Huidobro, Arrau, Neruda y otros.

Resulta de vital importancia cuando hablamos de la cultura visual del muro no descuidar éstas y otras exclusiones, ya que no sólo inciden en la noción de identidad que se presenta a los estudiantes, sino también empobrecen su vida mental a partir de un repertorio iconográfico muy limitado -no pocas veces sesgado-, que ciertamente proyecta una visión muy parcial en contraste con la enorme diversidad visual a la que los estudiantes tienen acceso fuera del establecimiento escolar.

Asimismo, tampoco hay que descuidar el uso que se hace de imágenes formativas, publicitarias o religiosas, ya que todas ellas proyectan nociones valóricas que, en cuanto tales, excluyen otros valores. Tal como sugiere la cultura visual, no existen imágenes puras que no expresen explícita o implícitamente algún tipo de significado, discurso o ideología. Por lo tanto, lo dicho puede ser extrapolable a todas las imágenes revisadas, lo que ameritaría una investigación más específica.

La necesidad de prestar mayor atención a las imágenes de las salas de clases no se limita a una revisión ideológica, como sugiere el párrafo anterior, también se requiere mayor investigación acerca de su uso e interés en el contexto pedagógico. Las imágenes constituyen un recurso importante para contribuir al proceso de enseñanza, y la extensiva presencia de éstas en los establecimientos visitados revela que son especialmente consideradas por los docentes. Sin embargo, parece no haber mucha reflexión sobre sus criterios de selección y su uso específico por parte de la comunidad escolar. En este sentido, se requiere aportar mayor investigación y discusión acerca del tipo de visualidades que pueden contribuir de un modo más relevante y pertinente a los objetivos fundamentales y los contenidos mínimos que propone el currículo escolar, así como también a la formación general de los estudiantes.

\section{REFERENCIAS BIBLIOGRÁFICAS}

Augustowsky, G. (2003). Las paredes del aula. Un estudio del espacio dispuesto por docentes y alumnos/as en la escuela primaria. Arte, Individuo y Sociedad, vol. 15, 39-59.

Alpers, S. (1983). The Art of Describing: Dutch Art in the Seventeenth Century. Chicago: University of Chicago Press.

Apple, M. \& King, N. (1983). What Do Schools Teach? In H. Giroux \& D. Purpel (Eds.), The Hidden Curriculum and Moral Education (pp. 82-99). Berkeley, California: McCutchan Publishing Corporation.

Bryson, N. (1988). The Gaze in the Expanded Field. In H. Foster (Ed.), Vision and Visuality (pp. 87-114). Washington: Bay View Press.

Clark, A., McQuai, S. \& Moss, P. (2003). Exploring the Field of Listening to and Consulting with Young Children. Research Report RR445. Department of Education and Skills Research: Birkbeck University of London.

Cornbleth, C. (1984). Beyond Hidden Curriculum? Journal of Curriculum Studies, vol. 16, n. 1, 29-36. 
Dikovitskaya, M. (2006). Visual Culture: The Study of the Visual after the Cultural Turn. Massachusetts: MIT Press.

Haapala, A. (2005). On the Aesthetic of the Everyday. In A. Light \& J. Smith (Eds.), The Aesthetics of Everyday Life (pp. 39-55). New York/Chichester: Columbia University Press.

Jackson, P. (1968). Life in Classrooms. New York: Holt, Rinehart \& Row.

Mandoki, K. (2007). Everyday Aesthetics: Prosaics, the Play of Culture and Social Identities. Aldershot/Burlington: Ashgate. (1994). Prosaica: Introducción a la Estética de lo Cotidiano. México D.F: Grijalbo.

Margolis, E. (1999). Class Pictures: Representations of Race, Gender and Ability in a Century of School Photography. Visual Sociology, vol. 14, n. 1, 7-38.

Mirzoeff, N. (1999). An Introduction to Visual Culture. London: Routledge.

Orellana, M. y Martínez, M. (2010). Educación e Imagen: Formas de modelar la realidad. Serie: Itinerario y Memoria del Bicentenario. Archivo Visual del Museo de la Educación Gabriela Mistral.

Read, M. (2010). Contemplating Design: Children's Preferences about Classroom Design. Creative Education, vol. 1, n. 2, 75-80.

Rose, G. (2001). Visual Methodologies. London: Sage.

Saito, Y. (2007). Everyday Aesthetics. New York: Oxford University Press.

Schein, E. H. (1997). Organisational Culture and Leadership. London: Jossey-Bass. 